\title{
Detection of Respiratory Viral Antigens in Nasal Swabs of Bovine by Sandwich ELISA
}

\begin{abstract}
Bovine Respiratory diseases are responsible for economic losses in livestock industry worldwide. The present study aiming to investigate the occurrence of respiratory viral antigens of Bovine herpesvirus-1 (BoHV-1), Bovine respiratory syncytial virus (BRSV), Bovine viral diarrhoea virus (BVDV) and Bovine parainfluenza 3 virus (BPI3V) in bovines and describe the distribution of respiratory viruses in unvaccinated animals in Punjab. A total of 55 nasal swab samples were collected from the cattle and buffaloes exhibiting the clinical signs of respiratory disease. All samples were tested for the detection of all four viral antigens by commercially available sandwich ELISA kit. BoHV-1 and BPI3V antigen were detected in 1 and 3 samples with the percentage of 1.8 and 5.4 , respectively, whereas none of the sample was found positive for BRSV and BVDV antigen. The present study concluded the existence of BoHV-1 and BPI3V infection in respiratory tract and plays the important role in the respiratory viral infections of bovines. This study suggests the prevention measures should be taken to control the economic losses due to respiratory diseases in cattle and buffaloes.
\end{abstract}

Key words: BoHV-1, BPI3V, BRSV, BVDV, Respiratory disease, Sandwich ELISA.

\section{INTRODUCTION}

Livestock sector has remarkable contribution in the national economy and emerged as a tool for socio economic development of the farming community. Dairy farming is now not only for household consumption but also as a source of supplementary income to the small and marginal farmers. India is a largest milk producer in the world and it can continue to hold the first position if some of the diseases affecting the productivity of the animals is taken care. Respiratory and reproductive disorders in dairy animals due to various etiological agents had led to severe economic losses to farmer in terms of decrease milk production as well as loss of feedlot animals.

Bovine respiratory diseases (BRD) occur all over the world and considered to be the major cause of morbidity and mortality within feedlot and dairy cattle (Iglseder et al., 2011). It is a multifactorial disease, such as stress due to weaning, transportation, pooling of cattle from multiple sources, dusty conditions, parasitism, concurrent diseases and weather extremes and environmental factors ultimately resulting in bronchopneumonia (Klima et al., 2014). Respiratory viruses viz. bovine herpes virus-1 (BoHV-1), bovine viral diarrhea virus (BVDV), bovine respiratory syncytial virus (BRSV) and Bovine Para influenza 3 virus (BPI3V) are the most important viral agents that cause respiratory infection in bovine worldwide.

Bovine Herpesvirus-1 (BoHV-1) belongs to family Herpesviridae, subfamily Alpha herpesvirinae. It is an economically important disease characterized by severe inflammation of upper respiratory tract together with dyspnoea, depression, nasal flow and deconditioning in cattle and buffaloes (Yavru et al., 2005). Besides this, infection may cause acute gastroenteritis, conjunctivitis, encephalitis, abortion, mastitis and repeat breeding in cattle.
Department of Veterinary Microbiology, Guru Angad Dev Veterinary and Animal Science University, Ludhiana-141 004, Punjab, India. ${ }^{1}$ Department of Veterinary Microbiology, College of Veterinary Science and AH Mhow-453 446, Madhya Pradesh, India.

Corresponding Author: Rakhi Gangil, Department of Veterinary Microbiology, College of Veterinary Science and AH Mhow-453 446, Madhya Pradesh, India. Email: rgangil@gmail.com

How to cite this article: Gangil, R., Kaur, G. and Dwivedi, P.N. (2020). Detection of Respiratory Viral Antigens in Nasal Swabs of Bovine by Sandwich ELISA. Indian Journal of Animal Research. 54(3): 354-358.

Submitted: 20-12-2018 Accepted: 23-07-2019 Published: 04-10-2019

Bovine viral diarrhea virus (BVDV) is a Pestivirus in the Flaviviridae family and it causes disease in bovines and characterized with respiratory symptoms, abortions, congenital anomalies, still birth and birth of persistently infected carrier animals and can lead to fatal mucosal disease (Bedekovic et al., 2013).

Bovine respiratory syncytial virus (BRSV) is a member of family Paramyxoviridae, genus Pneomovirus. BRSV infection is characterized with dyspnea, coughing, rhinitis, nasal discharge, fever, bronchiolitis, edema emphysema and in some cases disease progressing to severe pronchopneumonia may end with death (Ellis et al., 2001). Bovine Parainfluenza-3 virus (BPI3V) is also associated with respiratory infections, characterized by rhinitis, acute and silent fever nasal secretions (Solis-Calderon et al., 2003). It is a member of family Paramyxoviridae and subfamily Paramyxovirinae. Parainfluenza virus causes generally clinical and subclinical infections and this infection predispose the host to secondary bacterial infections and other viral infections may lead to death. 
Diagnosis of these viral pathogens have been made by various methods such as Enzyme Linked Immunosorbant Assay (ELISA), Serum Neutralization Test (SNT), Fluorescent Antibody test (FAT), Polymerase Chain Reaction (PCR) and Reverse Transcriptase PCR (RT-PCR). It has been opined that virus isolation is a gold standard and more sensitive for antigen detection in diagnosis, but it is time consuming, expensive and cumbersome procedure than ELISA and requires skilled personnel and established specified laboratory for cell culture (Fulton and Confer 2012). However ELISA has been test of choice for detection of antigen and antibody due to advantage to perform this test within a short time frame in the laboratory and is more efficient in the differential diagnosis as combined infection can also be detected simultaneously for different associated viral agents (Avci et al., 2014). The present study planned to detect the various respiratory viral antigens in nasal excretions of cattle and buffaloes and determine the BRD occurrence by sandwich ELISA.

\section{MATERIALS AND METHODS Sample collection}

A total of 55 nasal swab samples were collected in PBS from cattle and buffaloes exhibiting clinical signs of respiratory infections viz., coughing, depression, fever, nasal and ocular discharge, and anorexia during November 2016 to March 2018 from different Gaushalas in and around Ludhiana and Teaching Veterinary Clinical Complex, College of Veterinary Science, Guru Angad Dev Veterinary Science University Ludhiana, Punjab. Two $\mathrm{ml}$ of each sample were centrifuged at $825 \times \mathrm{g}$ for 15 minutes. Supernatant were collected and stored at $-20^{\circ} \mathrm{C}$ for further use. All the applications were performed under strict sterile conditions.

\section{Sandwich ELISA}

Nasal swab samples were analyzed for detecting mentioned viral antigens by a commercially available sandwich ELISA (Biox Diagnostics, Pulmotest Respiratory Tetra ELISA kit, Belgique) where detection of these agents can be assayed simultaneously from a single sample. The test was performed in Virology laboratory of Department of
Microbiology, College of veterinary Science, Guru Angad Dev Veterinary Science University Ludhiana, Punjab.

The sandwich ELISA was performed as per manufacturer instructions. The plates were read on an ELISA reader (Thermo, USA) at 450nm. The optical density (OD) in well coated with viral antibody was corrected by subtracting the OD value of corresponding negative control. Percent positivity values of sample were calculated as given below:

$$
\frac{S}{P} \%=\frac{O D_{\text {corrected value of sample }} \times 100}{O D_{\text {corrected value of positive control }}}
$$

Samples value was then compared with positive reference supplied with manufacturing kit.

\section{RESULTS AND DISCUSSION}

Bovine respiratory disease (BRD) is a major problem of cattle and buffaloes affecting all ages of animals worldwide and causes economic loss for producers (Houe, 2003). In present study, specific BoHV-1 antigen was detected in one $(1.8 \%)$ sample and $3(5.4 \%)$ samples were found positive for BPI3V antigen among all tested samples (Fig 1). However none of the sample was positive for BRSV and BVDV antigen. Not a solitary sample tested showed positive reaction for presence of two antigens concomitantly.

The serologic and virologic evidence of BoHV-1 infection caused by respiratory viruses has been demonstrated previously (Majumdar et al., 2015; Patil et al., 2017). The present study revealed $1.8 \%$ occurrence of BoHV-1 antigen in sandwich ELISA. Similarly, Iscan and Duman (2011) reported $0.8 \%$ (2/250) prevalence of BoHV-1 antigen in dairy cattle from nasal swab samples. While in the serological part of their study of same sampled animals revealed $21.2 \%$ prevalence of BoHV-1 specific antibody. The lower rate of detection of BoHV-1 viral antigen in present study by ELISA may be because of latency of virus at a time of collection of nasal swab. BoHV-1 has tendency to become latent in ganglion of infected animals and shedding of virus in nasal secretions/ viraemia occurs only after reactivation of virus in immunocompromised host or fresh infection (OIE, 2008). However, seroconversion invariably occurs at the time of

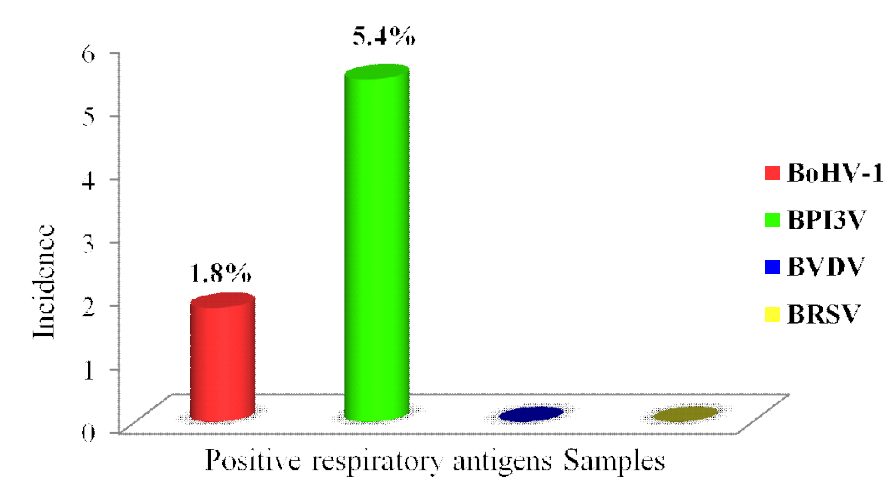

Fig 1: Incidence of respiratory virus antigens detected by in S-ELISA. 
initial infection and antibody titre persists for a longer duration, hence many study recorded higher seroprevalence. However, Singh et al. (2013) described the $11.1 \%$ prevalence of BoHV-1 infection in nasal swab samples of cattle of organized and unorganized herds from seven districts of Uttar Pradesh by using ELISA technique. In accordance of present study Ranganatha et al. (2013) also reported lower incidence of BoHV-1 from nasal swabs in their study and suggested it may be due to lower concentration of virus excreted from respiratory route. The number of antigen positive samples could have been increased if repeated swabs would have been taken from the suspected animals because the maximal virus shedding occurs between third and sixth days in acute phase of disease (OIE, 2008).

Edwards et al. (1985) experimentally inoculated the calves with BoHV-1 and noticed that by antigen detection ELISA is feasible only during pyrexic phase, which lasts for few days only. Collins et al. (1988) evaluated antigen capture ELISA for detection of BoHV-1 antigen in nasal swab specimens and it was judged that ELISA was found to be useful for diagnosis of BoHV-1 antigen when nasal swab specimens were collected during first five days of the infection, when clinical signs were the most apparent. Moreover, sampling in this study was done in all seasons. BoHV-1 infection prevalence was reported to be usually lower in summer than in the other seasons (Woodbine et al., 2009).

Bovine parainfluenza 3 virus (BPI3V) is one of the viruses known to cause respiratory infections. Widespread prevalence of BPI3V antibodies and detection of this virus in lungs were reported worldwide. Parainfluenza infection appears to predispose the host to secondary bacterial infections and it has also been shown to play a role in shipping fever. In the present study, specific parainfluenza antigen was detected in $5.4 \%$ of nasal samples by using sandwich ELISA, this finding in accordance with Goswami (2016), who reported $4.83 \%$ of parainfluenza infection in lung tissues of bovines. Sex wise incidence also recorded in current study. In present study higher percentage was observed in male $(9.1 \%)$ then female $(4.5 \%)$ in bovines among overall male and female tested respectively (Table 1). However, Noori et al. (2014) recorded higher BPI3V infection $20 \%(20 / 100)$ in pneumonic lung tissue by sandwich ELISA technique in Sudan. In their study, $19.1 \%$ positive for male while $21.9 \%$ positive for female. Parainfluenza infection is hard to diagnose due to milder clinical signs. Further death supervenes due to predominant secondary infections (Hagglund et al., 2006). Saeed et al. (2016) detected the parainfluenza virus 3 infection in lung tissues of cattle, sheep and goat in Sudan by using Ag-ELISA and reported 12.8\%,
$9.8 \%$ and $47.8 \%$ prevalence, respectively and also concluded that parainfluenza infection was causing economic losses due to its associated infection. According to present study, nasal swab can be good sample for diagnosis of disease in live animals while parainfluenza infection mainly reported in lung tissues of dead animals.

Bovine respiratory syncytial virus (BRSV) is also important virus affecting respiratory tract in cattle, especially in young calves. The serologic evidences of BRSV infections in India (Goswami et al., 2016 and Hazari et al., 2002) and other countries (Urban-Chmiel et al., 2013 and Saber et al., 1996) have been demonstrated. There are many studies conducted on lung tissues in comparison to nasal swab samples from live animals.

In present study, none of the samples were found positive for BRSV antigen by sandwich ELISA. This finding is in agreement with the observation recorded by Abdallah (2005), who tested 88 samples ( 37 nasal swabs and 51 lung tissue) by antigen detection ELISA and none of the nasal swab samples were found positive by ELISA while only one lung tissue found positive. However, Masot et al. (1993) considered ELISA as a diagnostic tool and most suitable technique for identifying BRSV antigen in the lung tissue. The detection of viral antigen from pneumonic lung tissue also tried by Avci et al. (2014) by antigen capture direct ELISA and $16.6 \%$ positivity recorded for BRSV antigen whereas could not find presence of BoHV-1, BPI3V and BVDV.

Our results were in accordance with Percivalle et al. (1989), who mentioned that ELISA lacks sensitivity in detection of BRSV antigen. Similarly, Quinting et al. (2007) compared different antigen detection tests for diagnosis of BRSV antigen, and suggested that ELISA is less sensitive then RT-PCR for BRSV antigen detection in lung tissues. Absence of BRSV antigen can also be explained by sample size, seasonal variation compared to previous findings (Van der Poel et al., 1994) that showes the incidence of BRSV in late autumn and winter.

In the current study, all nasal swab samples were detected as negative for BVDV antigen. Similarly, Goswami (2016) and Avci et al. (2014) were also not able to detect BVDV antigen in lung tissues of cattle by antigen detection ELISA. However, Ibrahim et al. (2008) examined 33 nasal swab samples of cattle for BVDV antigen detection by capture ELISA. In their study 54\% (18/33) prevalence of BVDV antigen were reported. BVDV infection was also reported in other samples such as peripheral blood mononuclear cells (PBMCs) of Indian cattle (Gupta et al., 2014) and milk samples of Korean dairy farms (Park et al. 2016) by Ag-Elisa. The serological evidence of BVDV was earlier reported in bovines from India (Puneet et al., 2012 and Selvaraj et al., 2007).

Table 1: Sex wise prevalence of bovine parainfluenza 3 virus antigen (BPI3V-Ag) in nasal swab samples by using sandwich ELISA.

\begin{tabular}{lccccccc}
\hline \multirow{2}{*}{ Total tested } & \multicolumn{5}{c}{ Males } & \multicolumn{3}{c}{ Females } & Total positive \\
\cline { 2 - 7 } & Tested & Positive & $\%$ & Tested & Positive & $\%$ & \\
\hline 55 & 11 & 1 & 9.10 & 44 & 2 & 4.54 & $3(5.45 \%)$ \\
\hline
\end{tabular}


The difference between our results and others may be due to time of sample collection that may be not at the time of acute infection or due to absence of antigen in samples. In the present study all the nasal swab samples were detected as negative for BRSV and BVDV, which may be either due to the animals showing clinical symptoms, might not be having presence/ infection of BRSV and BVDV or during the course neutralizing antibodies might have been produced and neutralized the virus from nasal tract. Since in present study, serological detection of antibodies was not aimed hence nothing can clearly be stated.

\section{CONCLUSION}

The present study showed the evidence of the presence of BoHV-1 and BPI3V infection among bovines in Punjab and also shedding the virus through respiratory route. The viral antigen can be detected from the upper respiratory tract of live animal. Further serological and virological examination should be done to investigate the viruses and preventive and control measure must be taken.

\section{ACKNOWLEDGMENT}

The authors are thankful to Director of Research for providing the necessary funds and facilities to conduct the research.

\section{REFERENCES}

Abdallah, A.F.M. (2005). Studies on Respiratory syncytial virus in cattle at Sharkia Governorate. MVSc Thesis, Zagazig University, Egypt.

Avci, O., Yavru, S. and Ekik. (2014). Detection of respiratory viral antigens in cattle lung tissues by direct ELISA. Animal and Veterinary Sciences. 5: 146-149.

Bedekovic, T., Lemo, N., Barbic, L., Cvetnic, Z., Lojkic, I., Benic, M., Cac, Z., Lojkic, M. and Madic, J. (2013). Influence of category, herd size, grazing and management on epide-miology of bovine viral diarrhoea in dairy herds. Acta Veterinaria Brno. 82: 125-130.

Collins, J.K., Ayers, V.K. and Carman, J. (1988). Evaluation of an antigen capture ELISA for the detection of bovine herpesvirus type 1 shedding from feedlot cattle. Veterinary Microbiology. 2: 101-107.

Edwards, S., Chasey, D. and White, H. (1985). Experimental infectious bovine rhinotracheitis: comparison of four antigen detection methods. Research in Veterinary Science. 1: 42-45.

Ellis, J., West. K., Konoby, C., Leard, T., Gallo, G., Conlon, J. and Fitzgerald, N. (2001). Efficacy of an inactivated respiratory syncytial virus vaccine in calves. Journal American Veterinary Medicine Association. 218: 1973-1980.

Fulton, R.W. and Confer, A.W. (2012). Laboratory test description for bovine respiratory diagnosis and their strengths and weaknesses: gold standards for diagnosis, do they exist? Canadian Veterinary Journal. 7: 754-761.

Goswami, P. (2016). Pathoepidemology of important common pathogens of Bovine in Punjab. Doctoral Thesis. Guru Angad Dev Veterinary and Animal Science University, Ludhiana pp 80-82.
Goswami, P., Banga, H. S., Deshmukh, S., Singh, N. D., Mahajan, V. and Brar, R. S. (2016). Sero-prevalence of bovine respiratory syncytial virus in bovine in Punjab, North India. Journal of Animal Research. 1: 67-73.

Gupta, V., Mishra, N., Rajukumar, K., Behera, S.P. and Dubey, P. (2014). Detection of bovine viral diarrhoea virus (BVDV) in peripheral blood mononuclear cells (PBMCs) of BVDV antibody positive Indian cattle following mitogen stimulation. Indian Journal of Animal Science. 84: 156-158.

Hagglund, S., Svensson, C., Emanuelson, U., Valarcher, J. F. and Alenius, S. (2006). Dynamics of virus infections involved in the bovine respiratory disease complex in Swedish dairy herds. Veterinary Journal. 172: 320-328.

Hazari, S., Panda, H. K., Kar, B. C. and Das, B. R. (2002). Comparative evaluation of indirect and sandwich ELISA for the detection of antibodies to bovine respiratory syncytial virus (BRSV) in dairy cattle. Comparative Immunology, Microbiology and Infectious Diseases. 25: 29-68.

Houe, H. (2003). Economic impact of BVDV infection in dairies. Biological. 31: 137.

Ibrahim, M. I., Desawy, O. M., Ali, N. O. and Nabi, S. S. (2008). Detection and isolation of bovine viral diarrhea in cattle by using different virological methods. Egypt Journal of Comparative Pathology and Clinical Pathology. 3: 148- 160.

Iglseder, A., Franz, S., Benetka, V., Mostl, K., Latif, M., Walk, K. and Baumgartner, W. (2011). Diagnosis of bovine viral respiratory diseases. Schweiz Arch Tierheilkd. 10: 441-447.

Iscan, U. T. and Duman, R. (2011). Bovine Herpesvirus Type 1 (BHV-1) Prevalance in Dairy Cattle. Journal of Animal and Veterinary Advances. 12: 1523-1525.

Klima, C.L., Zaheer, R., Booker, C.W., Hendrick, S., Alexander, T. W. and McAllister, T.A. (2014). Pathogens of bovine respiratory disease in North American feedlots conferring multidrug resistance via integrative conjugative elements. Journal of Clinical Microbiology. 2: 438-448.

Majumdar, S., Ramakrishnan, M. A. and Nandi, S. (2015). Infectious Bovine Rhinotracheitis: An Indian Perspective. International Journal of Current Microbiology and Applied Sciences.10: 844-858.

Masot, A.J., Gomez, T.C., Tovar, I., Gazquez, A. and Redondo, E. (1993). Location of bovine respiratory syncytial virus antigens in the lung of experimentally infected lambs: comparative study using indirect fluorescent antibody test, avidine biotin peroxidase complex and transmission electron microscopy. European Journal of Histochemistry. 37: 75-82.

Noori, Y. M., Intisar, K. S., Nasa, E. M. and Ali, Y. H. (2014). Detection and isolation of bovine Pparainfluenza virus Type 3 (PIV3) in cattle in North Kordofan State, Sudan. Journal of Science and Technology. 15: 70-78.

Office Internationale Des Epizootics (2008). Manual of Diagnostic Tests and Vaccines for Terrestrial Animals. OIE, Paris, France. 1343.

Park, H.J., Kim, G.D., Lee, C.H., Kang M.H. and Min, K.S. (2016). Analysis of bovine viral diarrhea virus in Korea dairy farms. Indian Journal of Animal Research. 50: 224-229.

Patil, S.S., Prajapati, A., Krishnamoorthy, P., Desai, G.S., Reddy, G.B.M., Suresh, K.P. and Rahman, H. (2017). Seropre-valence of infectious bovine rhinotracheitis in organized 
dairy farms of India. Indian Journal of Animal Research. 51: 151-154.

Percivalle, E., Zavattoni, M., Revello, M. G., Mariani, G., Scaravelli, C. and Gerna, G. (1989). Rapid detection of respiratory syncytial virus in nasopharyngeal secretions by immuno-fluorescence and ELISA does not justify discontinuation of virus isolation. Microbiologica. 2: 203-213.

Puneet, V., Qureshi, S.D., Bhatia, A.K., Pradhan, A.K, Mishra N and Bhatia S. (2012). Molecular and antibody based diagnosis of bovine viral diarrhea virus (BVDV) associated with cattle from Mathura, Utter Pradesh India. Applied Biological Research. 14: 215-19.

Quinting, B., Robert, B., Letellier, V.,Boxus, M., Kerkhofs, P., Schynts, F. and Collard, A. (2007). Development of a 1-step enzyme linked immunosorbent assay for the rapid diagnosis of bovine respiratory syncytial virus in postmortem specimens. Journal of Veterinary Diagnostic Investigantion. 3: 238-43.

Ranganatha, S., Rathnamma, D., Patil, S.S., Chandranaik, B.M., Isloor, S., Veeregowda, B.M., Narayanabhat, M. and Srikala (2013). Isolation and molecular characterization of Bovine Herpes Virus-1 by Polymerase Chain Reaction. Indian Journal of Animal Research. 47(4): 340-43.

Saber, M.S., Salem, A.A., Mohamed, S.A.H., Hadia, A.H.H., Nawal, A.M., Mossa, A.A. and Fatheia, M.M. (1996). Isolation, identification and seroconversion studies on BRSV in Egypt. Veterinary Medical Journal Giza. 44: 735- 747.

Saeed, I. K., Ali, Y.H., Taha, K.M., Mohammed, N.E., Noori, Y. M., Mohamed, B.A., Mohammad, O.I., Elmagboul, S.B. and Ghazali, F.A. 2016. Parainfluenza virus 3 infection in cattle and small ruminants in Sudan. Journal of Advanced Veterinary and Animal Research. 3: 236-41.
Selvaraj, J., Murali,M. B., Balachandran, C., Mishra, N., Pradhan, H.K. (2007). Seroprevalence of bovine viral diarrhoea in buffaloes at Chennai. Indian Journal of Veterinary Pathology. 31: 180.

Singh, R., Verma, A.K., Sharma, B. and Yadav, S.K. (2013). Detection of bovine herpes virus-1 (BHV-1) infection in cattle by antigen detection ELISA and multiplex PCR. Advances in Animal and Veterinary Science. 3S: 12-16.

Solis-Calderon, J.J., Segura-Correa, V.M., Segura-Correa, J.C. and Alvarado-Islas, A. (2003). Seroprevalence of and risk factors for infectious bovine rhinotracheitis in beef cattle herds of Yucatan, Mexico. Preventive Veterinary Medicine. 57: 199-208.

Urban-Chmiel, R., Wernicki, A., Puchalski, A., Stegierska, D., Grooms, D.L. and Barbu, N. I. (2013). Rapid detection of bovine respiratory syncytial virus in Poland using a human patient side diagnostic assay. Transboundry and Emerging Diseases. 62: 407-10.

Van der Poel, W.H., Brand, A., Kramps, A. and van Oirschot, J.T. (1994). Respiratory syncytial virus infections in human beings and in cattle. Journal of Infectious Disease. 29: 215-228.

Woodbine, K.A., Medley, G.F., Moore, S.J., Ramirez-Villaescusa, A.M., Mason, S. and Green, L. E. (2009). A fouryear longitudinal seroepidemiological study of bovine herpsvirus type -1 (BHV-1) in adult cattle in 107 unvaccinated herds in south-west England. BMC Veterinary Research. 5: 5-5.

Yavru, S., Simsek, A., Yaplico, O. and Kale, M. (2005). Serological evaluation of viral infection in bovine respiratory tract. Acta Veterinary. 2: 219-26. 